\title{
ORTHONORMAL SEQUENCES AND TIME FREQUENCY LOCALIZATION RELATED TO THE RIEMANN-LIOUVILLE OPERATOR
}

\author{
AMRI BESMA AND HAMMAMI AYMEN
}

Abstract. For every real number $p>0$, we define the $p$-dispersion $\rho_{p, v_{\alpha}}(f)$ of a measurable function $f$ on $\left[0,+\infty\left[\times \mathbb{R}\right.\right.$, where $v_{\alpha}$ is some positive measure. We prove that for every orthonormal basis $\left(\varphi_{m, n}\right)_{(m, n) \in \mathbb{N}^{2}}$ of $L^{2}\left(d v_{\alpha}\right)$, the sequences $\left(\rho_{p, v_{\alpha}}\left(\varphi_{m, n}\right)\right)_{(m, n) \in \mathbb{N}^{2}}$, $\left(\rho_{p, v_{\alpha}}\left(\widetilde{\mathscr{F}}_{\alpha}\left(\varphi_{m, n}\right)\right)\right)_{(m, n) \in \mathbb{N}^{2}}$ can not be simultaneously bounded, where $\widetilde{\mathscr{F}}_{\alpha}$ is some Fourier transform. The main tool is a time frequency localization inequality for orthonormal sequences in $L^{2}\left(d v_{\alpha}\right)$.

On the other hand, we construct an orthonormal sequence $\left(\psi_{m, n}\right)_{(m, n) \in \mathbb{N}^{2}} \subset L^{2}\left(d v_{\alpha}\right)$ such that the sequence $\left(\rho_{p, v_{\alpha}}\left(\psi_{m, n}\right) \rho_{p, v_{\alpha}}\left(\widetilde{\mathscr{F}}_{\alpha}\left(\psi_{m, n}\right)\right)\right)_{(m, n) \in \mathbb{N}^{2}}$ is bounded.

Mathematics subject classification (2010): 42A38, 44A35.

Keywords and phrases: Orthonormal basis, Hilbert Schmidt operator, frequency localization, RiemannLiouville operator, Fourier transform.

\section{REFERENCES}

[1] B. AmRI AND L. T. RACHDI, The Littlewood-Paley $g$-function associated with the Riemann-Liouville operator, Ann. Univ. Paedagog. Crac. Stud. Math. 12 (2013), 31-58.

[2] B. AmRI AND L. T. RACHDI, Uncertainty principle in terms of entropy for the Riemann-Liouville operator, Bull. Malays. Math. Sci. Soc., doi .org/101007/s-40840-015-0121-5.

[3] B. AMRI AND L. T. RACHDI, Beckner Logarithmic Uncertainty principle for the Riemann-Liouville operator, Internat. J. Math. 24, no. 9 (2013) 1350070 (29 pages).

[4] B. AMRI AND L. T. RACHDI, Calderon-reproducing formula for singular partial differential operators, Integral Transforms Spec. Funct. 25, no. 8 (2014) 597-611.

[5] C. BACCAR, N. B. HAMADI AND L. T. RACHDI, Inversion formulas for the Riemann-Liouville transform and its dual associated with singular partial differential operators, Int. J. Math. Math. Sci. 2006 (2006) 1-26.

[6] C. BACCAR, N. B. HAMAdi AND L. T. RAChDi, Best approximation for Weierstrass transform connected with Riemann-Liouville operator, Commun. Math. Anal. 5, no. 1, (2008) 65-83.

[7] C. BACCAR AND L. T. RACHDI, Spaces of $D_{L^{p}}$-type and a convolution product associated with the Riemann-Liouville operator, Bull. Math. Anal. Appl., vol. 1, Iss. 3 (2009) 16-41.

[8] A. BEuRLing, The collected works of Arne Beurling, Birkhäuser., vol. 1-2, Boston, 1989.

[9] W. R. BLOOM AND H. HeYER, Harmonic analysis of probability measures on hypergroups, de Gruyter studies in mathematics 20, walter de Gruyter, Berlin-New York, 1995.

[10] A. Bonami, B. Demange, And P. Jaming, Hermite functions and uncertainty priciples for the Fourier and the widowed Fourier transforms, Rev. Mat. Iberoamericana, 19 (2003) 23-55.

[11] M. G. COWLING AND J. F. PRICE, Generalizations of Heisenberg's inequality in Harmonic analysis, (Cortona, 1982), Lecture Notes in Math., 992 (1983) 443-449.

[12] L. DE BRanges, Self-reciprocal functions, J. Math. Anal. Appl. 9 (1964) 433-457.

[13] A. ERDÉLYI et al., Tables of integral transforms, Mc Graw-Hill Book Compagny., vol. 2, New York, 1954. 
[14] A. ERdÉlYi, Asymptotic expansions, Dover publications, New-York, 1956.

[15] J. A. FAWCETT, Inversion of n-dimensional spherical averages, SIAM Journal on Applied Mathematics, no. 02, (1985), 336-341.

[16] G. B. Folland AND A. Sitaram, The uncertainty principle: a mathematical survey, J. Fourier Anal. Appl. 3 (1997) 207-238.

[17] G. H. HARDY, A theorem concerning Fourier transform, J. London. Math. Soc. 8 (1933) 227-231.

[18] S. Helgason, The Radon Transform, Birkhäuser, 2nd edition, 1999.

[19] H. HeLlsten AND L.-E. AndersSOn, An inverse method for the processing of synthetic aperture radar data, Inverse Problems 3, no. 1 (1987), 111-124.

[20] M. HERBERTHSON, A numerical implementation of an inverse formula for CARABAS raw data, Internal Report D30430-3.2, National Defense Research Institude, FOA, Box 1165; S-581 11, Linköping, 1986.

[21] Kh. Hleili, S. OMRI And L. T. RAChDi, Uncertainty principle for the Riemann-Liouville operator, Cubo, vol. 13, no. 03, (2011) 91-115.

[22] P. Jaming, A. M. PowelL, Uncertainty principles for orthonormal sequences, J. Funct. Anal. 243 (2007), 611-630.

[23] N. N. Lebedev, Special Functions and Their Applications, Dover publications, New-York, 1972.

[24] E. Malinnikova, Orthonormal sequences in $L^{2}\left(\mathbb{R}^{d}\right)$ and time frequency localization, J. Fourier Anal. Appl. 16, (2010), 983-1006.

[25] G. W. Morgan, A note on Fourier transforms, J. London. Math. Soc. 9 (1934) 178-192.

[26] S. OMRI AND L. T. RACHDI, An $L^{p}-L^{q}$ version of Morgan's theorem associated with RiemannLiouville transform, Int. J. Math. Anal., vol. 1, no. 17 (2007) 805-824.

[27] S. OMRI AND L. T. RACHDI, Heisenberg-Pauli-Weyl uncertainty principle for the Riemann-Liouville Operator, J. Inequal. Pure and Appl. Math. 9 (2008), Iss. 3, Art 88.

[28] L. T. RAChDi AND A. Rouz, On the range of the Fourier transform connected with RiemannLiouville operator, Ann. Math. Blaise Pascal, vol. 16, no. 2 (2009) 355-397.

[29] L. T. RAChdi, B. Amri And C. Chettaoui, $L^{p}$-Boundedness for the Littlewood-Paley g-Function Connected with the Riemann-Liouville Operator, KYUNGPOOK Math. J. 56 (2016), 185-220.

[30] H. S. SHAPIRO, Uncertainty principles for bases in $L^{2}(\mathbb{R})$, in: Proceedings of the Conference on Harmonic Analysis and Number Theory, CIRM, Marseille-Luminy, October 16-21 (2005).

[31] E. M. STEIN, Interpolation of linear operator, Trans. Amer. Math. Soc. 83, no. 2 (1956) 482-492.

[32] E. M. STEIN AND G. Weiss, Introduction to Fourier Analysis on Euclidean Spaces, Princeton University, New Jersey, 1971.

[33] K. TRIMÈche, Transformation intégrale de Weyl et théorème de Paley-Wiener associés à un opérateur différentiel singulier sur $(0,+\infty)$, J. Math. Pures Appl. 60 (1981) 51-98.

[34] K. TRIMÈCHE, Inversion of the Lions translation operator using genaralized wavelets, Appl. Comput. Harmon. Anal. 4 (1997) 97-112.

[35] G. N. Watson, A treatise on the theory of Bessel functions, Cambridge univ. Press., 2nd ed, Cambridge 1959. 